\title{
The 5 Dimensions of Problem Solving USING DinNa: CASE STUdy IN THE ELECTRONICS INDUSTRY
}

\author{
Mohammed Hamoumi ${ }^{1}$, Abdellah Haddout ${ }^{2}$ and Mariam Benhadou ${ }^{2}$ \\ ${ }^{1}$ PHD Student, Laboratory of Industrial Management, Energy and Technology of \\ Plastic and Composites Materials Hassan II University - ENSEM \\ Casablanca, Morocco \\ ${ }^{2}$ Professor, Laboratory of Industrial Management, Energy and Technology of \\ Plastic and Composites Materials Hassan II University - ENSEM \\ Casablanca, Morocco
}

\begin{abstract}
Based on the principle that perfection is a divine criterion, process management exists on the one hand to achieve excellence (near perfection) and on the other hand to avoid imperfection. In other words, Operational Excellence (EO) is one of the approaches, when used rigorously, aims to maximize performance. Therefore, the mastery of problem solving remains necessary to achieve such performance level.
\end{abstract}

There are many tools that we can use whether in continuous improvement for the resolution of chronic problems (KAIZEN, DMAIC, Lean six sigma...) or in resolution of sporadic defects (8D, PDCA, QRQC ...). However, these methodologies often use the same basic tools (Ishikawa diagram, 5 why, tree of causes...) to identify potential causes and root causes. This result in three levels of causes: occurrence, no detection and system.

The research presents the development of DINNA diagram [1] as an effective and efficient process that links the Ishikawa diagram and the 5 why method to identify the root causes and avoid recurrence. The ultimate objective is to achieve the same result if two working groups with similar skills analyse the same problem separately, to achieve this, the consistent application of a robust methodology is required. Therefore, we are talking about 5 dimensions; occurrence, non-detection, system, effectiveness and efficiency.

As such, the paper offers a solution that is both effective and efficient to help practitioners of industrial problem solving avoid missing the real root cause and save costs following a wrong decision.

\section{KEYWORDS}

Operational Excellence, DINNA Diagram, Double Ishikawa and Naze Naze Analysis, Ishikawa, 5 Way analysis, Morocco

\section{INTRODUCTION}

Previous research has identified methodologies using a set of methods that we can use to improve the results of each of the phases that continuous improvement projects must go through [2]. As problems become more complex, more structured tools are needed to support these steps, from characterizing the problem to put in place an action plan. These tools use divergent techniques, 
which help generate multiple alternatives, and convergent techniques that help analyze and filter the generated options [3] [4]. Some of the most cited methodologies are 8D [5] [6] [7] [8], PDCA[9] [10] [11] [12] [13] [14] [15] [16], DMAIC [17] [18] [19] [20] [21] [22] [11] and KAIZEN [23] [24] [25] [26] [27] [28]. However, Ishikawa [29] and 5 Way analysis [30] remain the most basic tools used in all those methodologies.

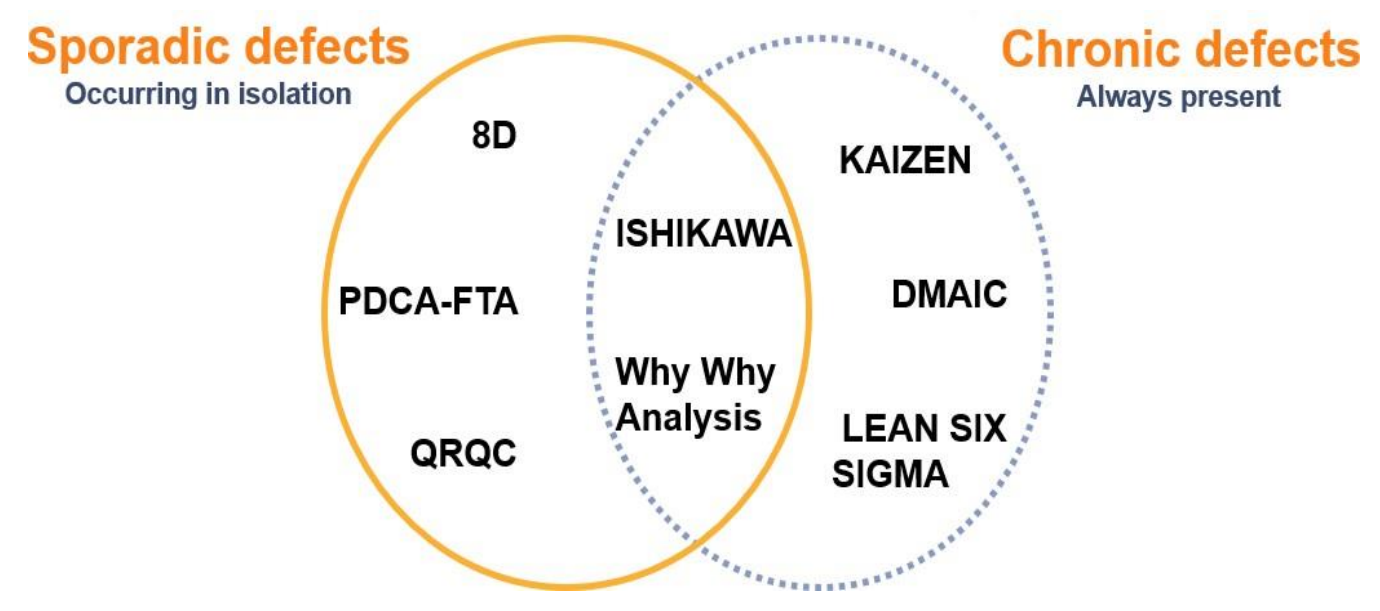

Figure 1. Common tools to all problem-solving methodologies

\section{Motivation \& Philosophy}

\section{Motivation}

The research is the result of several years of $8 \mathrm{D}$ methodology practitioner (more than 1200 reports over 15 years) on semiconductor, wiring systems and automotive industries. I hope that will be helpful and by the way, one cogitates (think deeply) item to develop in the future. I present the 5 dimensions experimental design of problem solving using DINNA Diagram : Double Ishikawa and Naze Naze Analysis, discussing the novel approach we have taken to defect and root cause classification and the mechanisms we have used to connect between the different diagrams. We then present the results of our analyses and describe the best way to get it. We conclude with lessons learned from the methodology and resulting ongoing improvement activities.

\section{Philosophy}

If we assume that we have two teamwork groups with similar skills both looking for the root cause of the same problem separately, how can we be sure that the two groups will achieve the desired result using the same methodology?

\section{DINNA DIAGRAM}

\section{Double Ishikawa Diagram}

The Ishikawa diagram [29] is one of Seven Basic Tools of Quality, (also called fishbone diagrams, herringbone diagrams, cause-and-effect diagrams, or Fishikawa) are causal diagrams created by Kaoru Ishikawa (1968) that show the causes of a specific event. This diagram illustrates the cause and effect diagram or 5ME (Material, Man, Machine, Method, Measure and 
Environment). For each branch all potential causes are described. Indeed, the purpose is to break down (in successive layers of detail) causes that potentially contribute to a particular effect.

Mostly if not always, we treat only the occurrence (why it happened) and we forget the nondetection (why it wasn't detected) root causes. That's why, double Ishikawa diagram is very important to complete the analysis. And, we keep the "Man" for the last, to not be influenced.

I chose the double Ishikawa form like "Figure. 2" to facilitate the connection with the why why analysis.

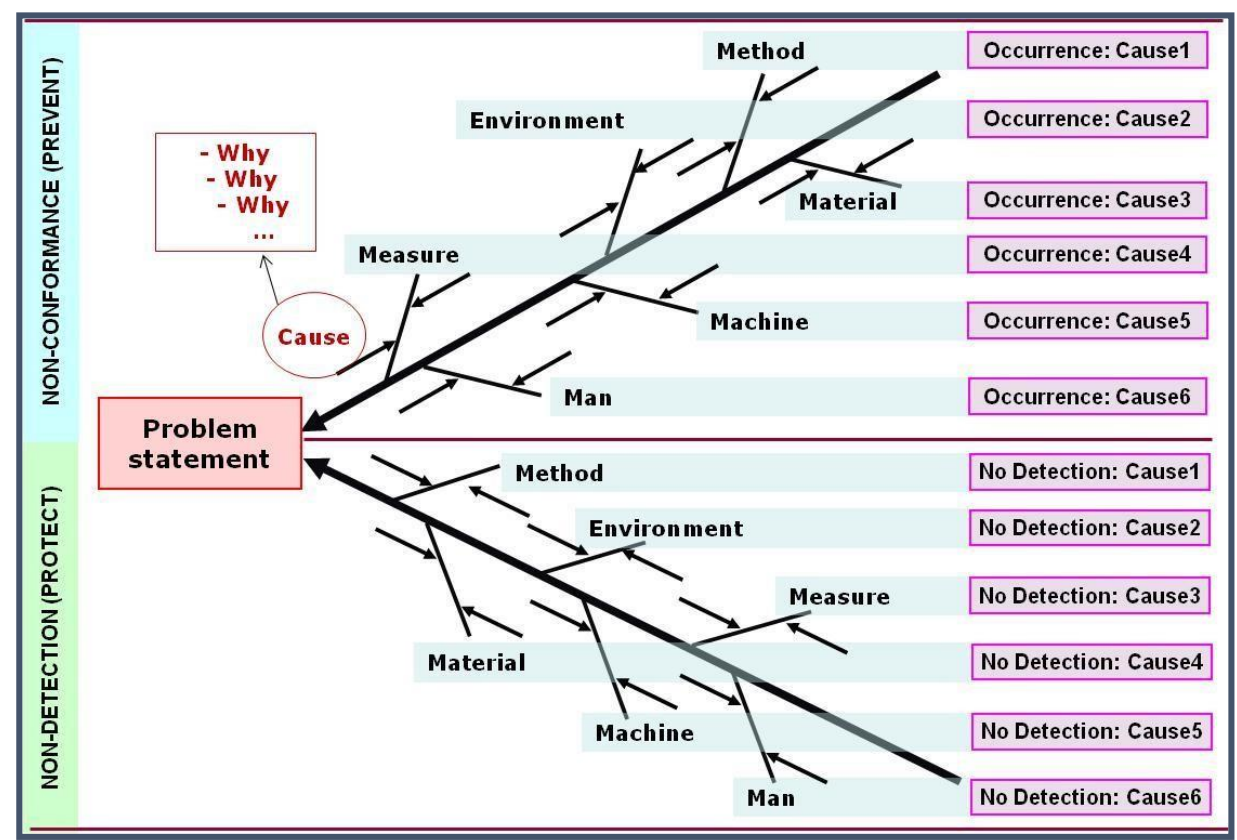

Figure 2. Double Ishikawa Diagram There are two ways to verify the causes, by reproducing the defect or by team voting.

By reproducing the defect: We try to reproduce the defect based on hypotheses given by team members, but this method is limited by time allocate to the analysis and also if there is combination of several causes.

By team voting: Sometimes it is very difficult to verify the causes by reproducing the defect. In this case, the team formulates hypotheses that can be objectively tested. The approach is that each team member gives a causes weight (3P, 2P, 1P) based on their feedback and expertise, and in the end we sum the points which giving a final number as shown in the example below "Figure. 3". 


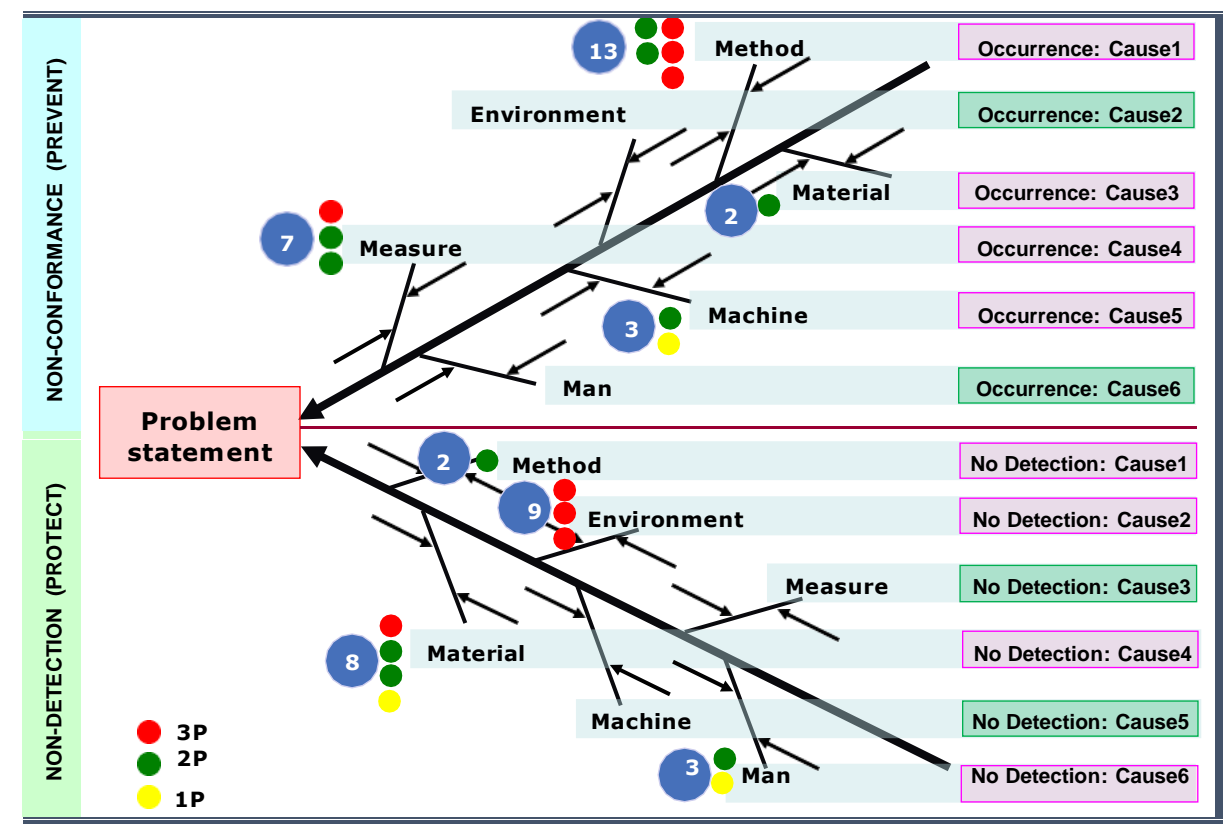

Figure 3. Double Ishikawa and the vote

\section{Naze Naze Analysis}

5 Why's are widely used to find the real root cause, invented by Taiichi Ohno [30] which was the great quality guru working for Toyota, 5 Why's are also called Naze Naze in Japanese (Naze=Why). The principal is to ask several times the question Why until you hit the real root cause.

And for sure, the question Why can be asked less or more than 5 times. Also, make sure the root cause is connected to the initial problem with a logical link.

Which is the Reel Root Cause?

- The reel root cause must be well described: need to be accurate, measurable, specific and without interpretation.

- The reel root cause is the one identified that satisfies the requirement of completely explaining the effect. It is the single verified reason that accounts for the problem.

- The reel root cause is supported by the facts without contradiction.

- The reel root cause is the one whose removal should make the effect stop permanently.

- The Double Ishikawa (or the list of initial causes) is the starting point. That could be the problem itself but that will be less accurate.

\section{Methodology:}

Step 1: select one initial cause from the Double Ishikawa. For each branch all potential causes are described: Advantage of this in description of a problem: you will not forget anything. 
International Journal of Data Mining \& Knowledge Management Process (IJDKP) Vol.11, No.5, September 2021

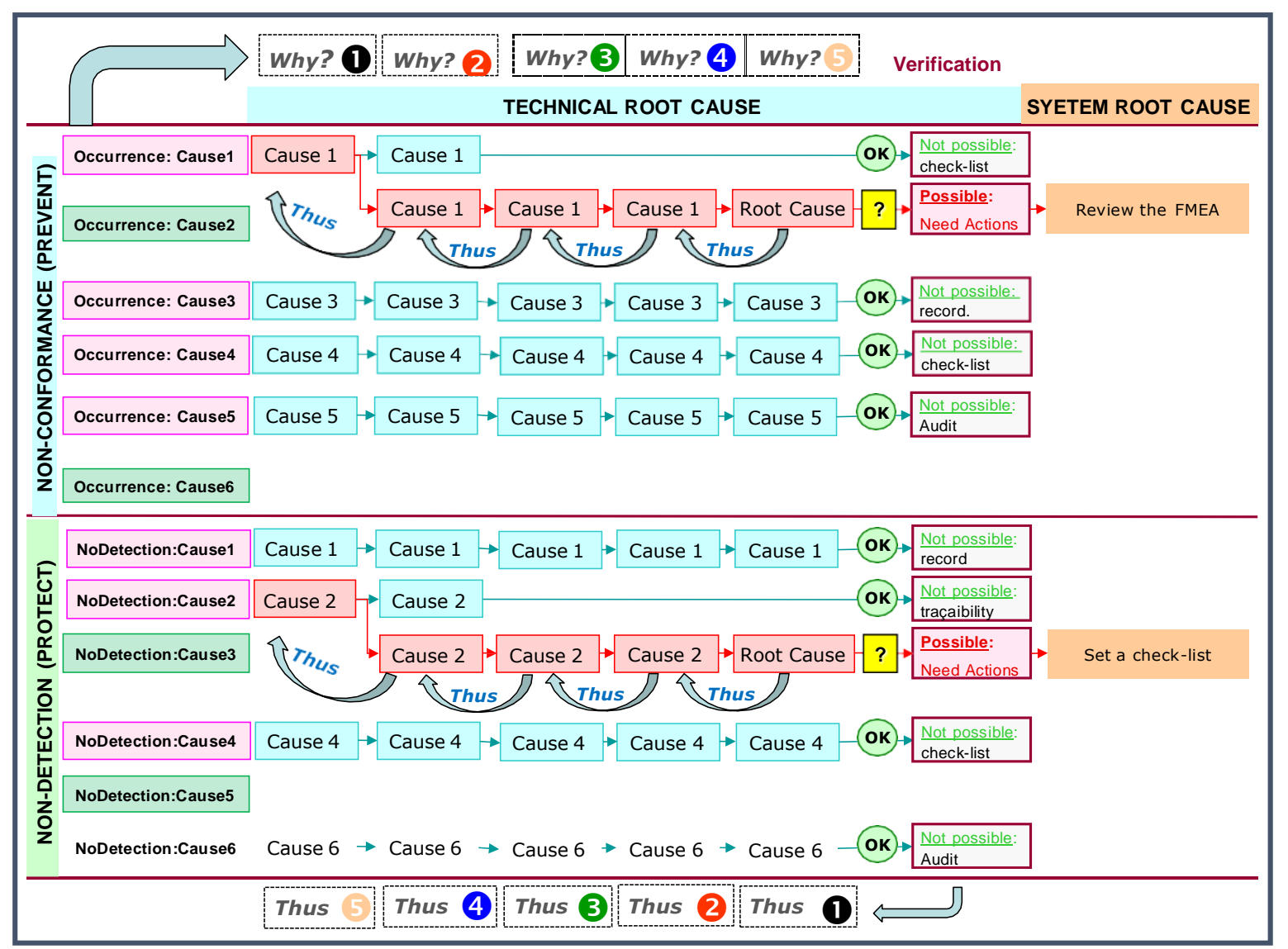

Figure 4. Naze Naze Analysis

Step 2: repeat "why" until the answer can trigger a countermeasure. It's important to note that the "5 Whys" technique can break into multiple chains when a particular "why?" has multiple answers. This is the time to apply the Pareto method and determine which pathway has the greatest effect in causing the performance gap. When choosing between two courses of action, it's better to address the causes with an $80 \%$ impact on the problem first, before dealing with causes that have a lesser impact. See below (Occurrence: cause 1, in the first why, we get two causes, one was verified as not possible the second one, guide us to the reel root cause).

Step 3: Ask «thus » at every cause to verify the root cause. In fact, to verify that the analysis is correct, you should be able to propose a countermeasure to the root cause and apply the word "thus" or "therefore" to verify that the countermeasure addresses each cause in the chain. This is what we call the "reversible" aspect of the 5 Why's to verify the reel root cause.

\section{Good example:}

"I was late" $\rightarrow$ why $\rightarrow$ because "my car did not start"

Do you mean "your car did not start so you were late"? Yes! so the cause is confirmed.

\section{Bad example:}

"I was late" $\rightarrow$ why $\rightarrow$ because "I had a party yesterday evening"

Do you mean "you had a party yesterday, so you were late"? 
Cannot be Yes because you may have a party and be just in time. Being late is due to something else $\rightarrow$ this cause is not confirmed.

\section{Three dimensions of Naze Naze Analysis}

The Naze Naze Analysis splits into 3 dimensions:

1) The Occurrence (non-conformity)

Why do we have the problem?

2) The Escape (non-detection)

Why did we not detect the problem?

3) The System (preventive \& predictive)

Why did the system allow this problem to happen?

Why did the system allow this problem to not be detected?

\section{Double Ishikawa and Naze Naze Analysis Diagram}

DINNA Diagram is a powerful problem-solving methodology which is an iterative effort that requires strong leadership, good teamwork, and relentless follow-through. If it were easy, you wouldn't need to spend time diving deep to understand the real root causes and solutions. You'd simply solve the problem.

In lean manufacturing, real root cause countermeasure tools are often used to help perform the necessary discovery and analysis, and to provide the insight needed to develop an effective and permanent solution. This approach is exactly what we found when we use DINNA Diagram, it will help you to gain time, to effectively determine the real root cause(s), and to avoid the recurrence.

The DINNA Diagram is complete resolving problem methodology if it is used correctly, we should not stop until ALL real root causes have been identified: Occurrence and Escape, Technical and System.

Remind that when the real root cause is identified is provides an opportunity to prevent it happening again thus reducing the possible recurrence, increasing customer satisfaction, etc...Finally, customers often require a 5 Why's from their supplier because they think that it is a key tool to find the real root cause and then to prevent recurrence. That's why; DINNA Diagram is well designed to force us to go down to the real root causes using fact-based links between the cause and the effect. 
International Journal of Data Mining \& Knowledge Management Process (IJDKP) Vol.11, No.5, September 2021

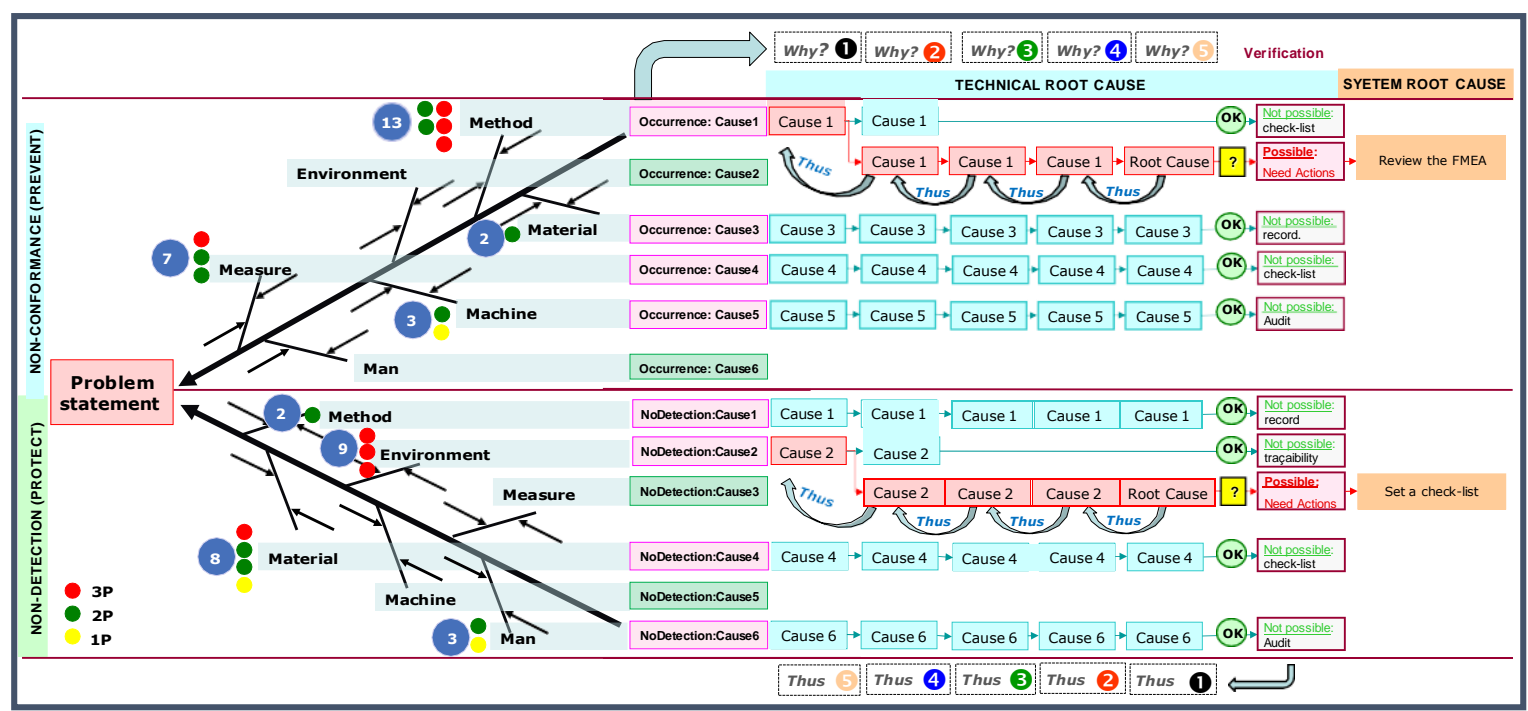

Figure 5. Double Ishikawa and Naze Naze Analysis Diagram

\section{The 5 dimensions of problem-solving using DINNA Diagram}

The robustness of any problem-solving tool cannot be achieved if it does not address the effectiveness and efficiency dimensions. Using the Dinna diagram rigorously, we identify the true root cause or the combination of several root causes. At this stage, an action plan is required, and the choice of appropriate actions is made based on a decision matrix which should consider the cost criterion alongside the quality and the deadline. Therefore, the efficiency remains mandatory for Operational Excellence mindset and this is the 4th dimension.

Finally, the 5th dimension is the effectiveness of the actions put in place to eradicate the problem, which can be verified by compliance audits and perfectly if no recurrence recorded.

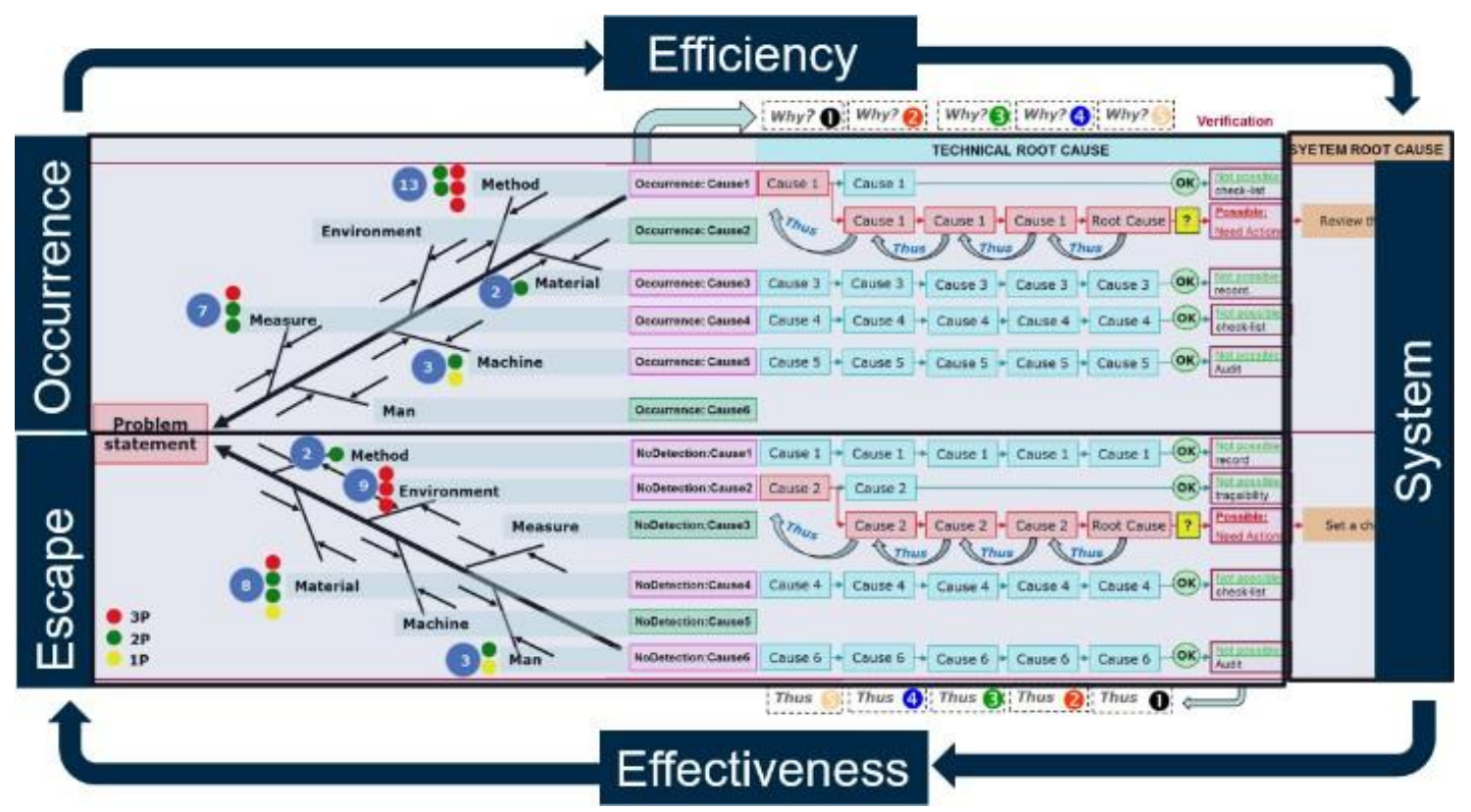

Figure 6. The 5 dimensions of problem-solving using DINNA Diagram 


\section{Practical case using the 5 dimensions of problem-solving using DINNA Diagram}

The example is a "Glue Bridging" on SO8 device which generates a short circuit due to die attach (in this case the output voltage is over specification).

\section{Real Time X-Ray Analysis :}

Sample were submitted to X-rays inspection, a glue bridge observed at pin\#2 also leading abnormal leakage during stimulating current or voltage signals.

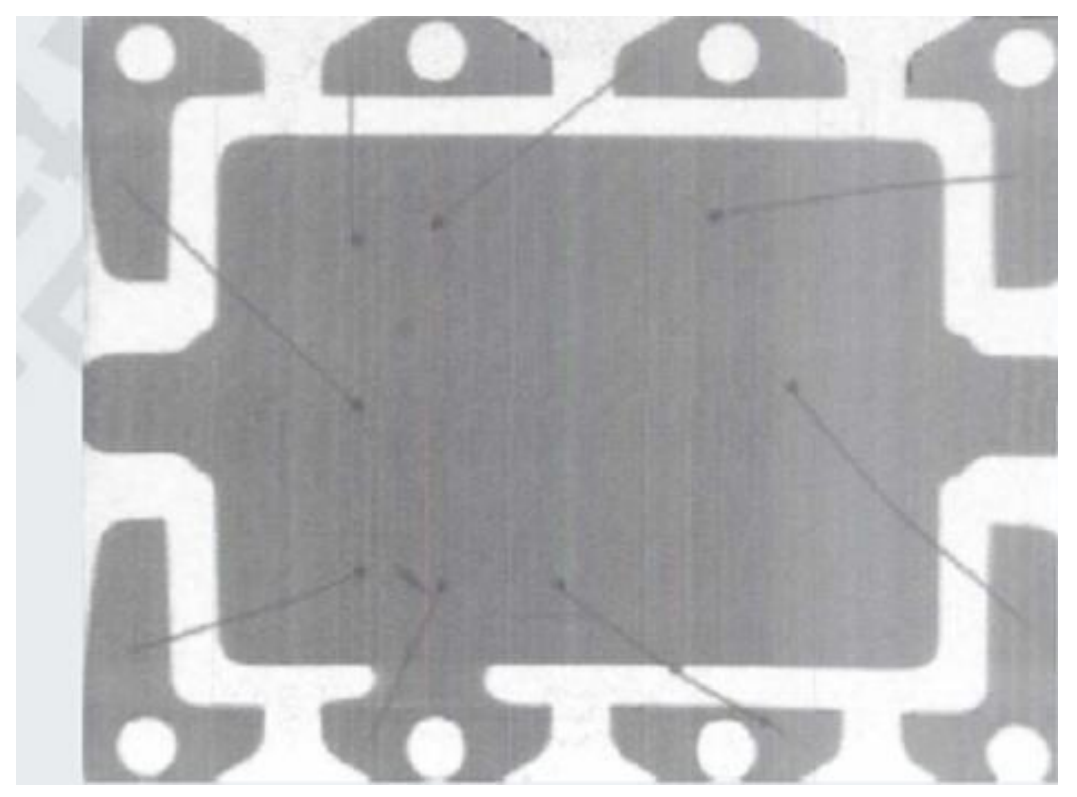

\section{Electrical Analysis:}

At our automatic electrical test, the device with glue bridging was confirmed as electrically reject with new program and good with old one.

The flow chart for this product is as follow:

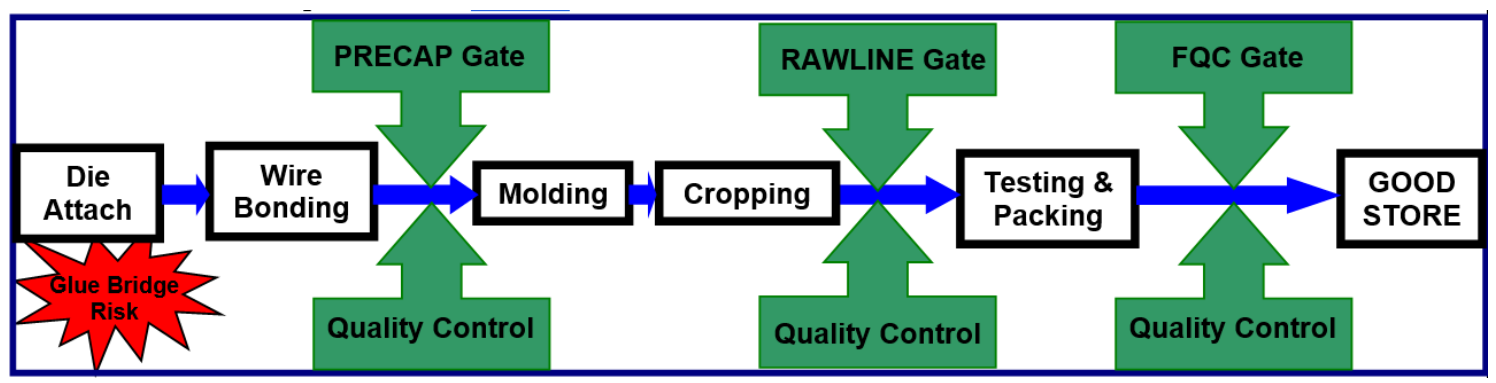

In order to understand the root cause of the defect, we perform DINNA Diagram \& Trials :

To be brief, we treat only the first dimension "Occurrence" : 
International Journal of Data Mining \& Knowledge Management Process (IJDKP) Vol.11, No.5, September 2021

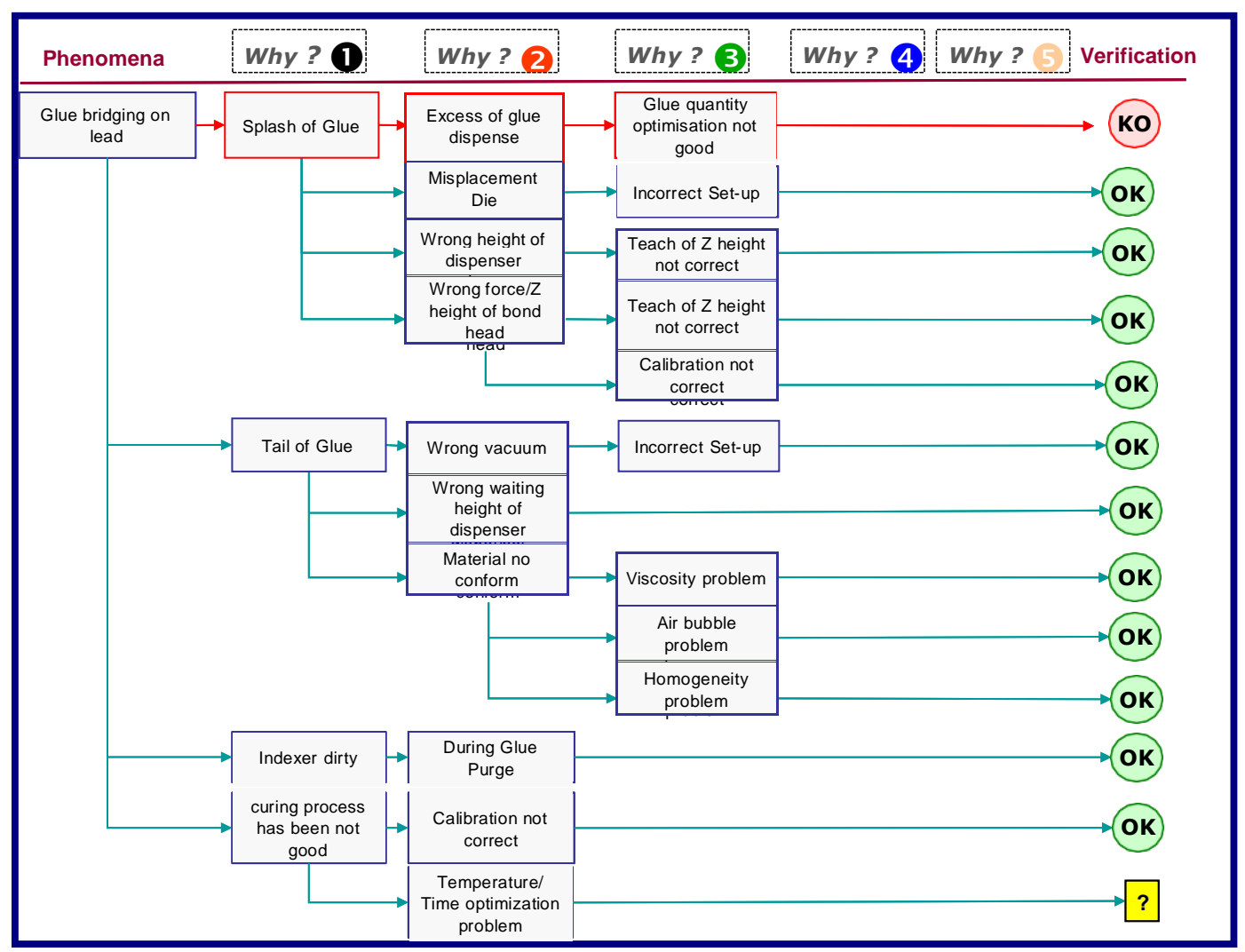

\section{Conclusion}

Basing on the analysis above we can conclude that Glue quantity optimization might generate similar defect as the received unit and on the reproduced defect units (see below).

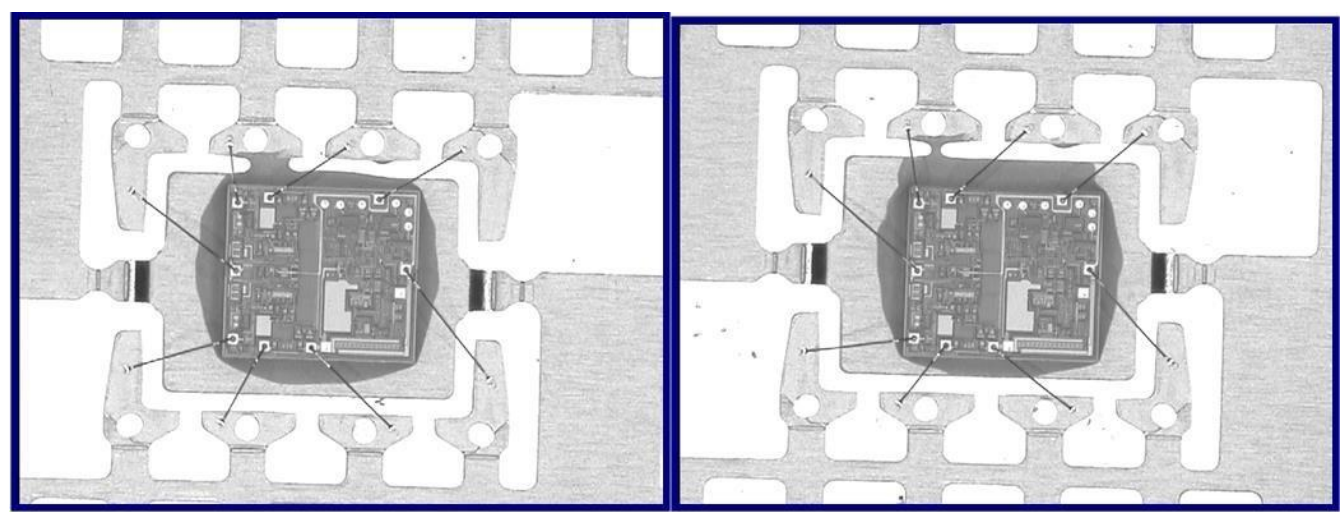

\section{Corrective action Implementation \& Verification:}

- Decrease of Glue quantity to avoid such glue bridging.

- Make DOE (Design Of Experiments) in curing process for Temperature/Time optimisation.

\section{Conclusions}

DINNA diagram has been tested for different problems in three sectors of the automotive industry: Semiconductor (80\% machine Vs. 20\% Human), Automotive suppliers (20\% machine 
Vs. $80 \%$ Human), and Car Maker (50\% machine Vs. 50\% Human). We will publish other practical cases in the future using the 5 dimensions of problem solving with DINNA diagram.

\section{REFERENCES}

[1] Hamoumi, M. (2017) Made in Morocco: DINNA Diagram (Double Ishikawa and Naze Naze Analysis). Proceedings of the International Conference on Industrial Engineering and Operations Management, 2017, :2180-2185 Language: English. IEOM Society.

[2] Tschimmel, K. (2012). Design thinking as an effective toolkit for innovation. Paper presented at the Proceedings of the XXIII ISPIM Conference: Action for Innovation: Innovating from Experience, Barcelona.

[3] Clune, S. J., \& Lockrey, S. (2014). Developing environmental sustainability strategies, the double diamond method of lca and design thinking: A case study from aged care. Journal of Cleaner Production, 85, 67-82. doi:https://doi.org/10.1016/j.jclepro.2014.02.003

[4] Smalley, A. (2018). Four types of problem solving. Cambridge: Lean Enterpdise Institute.

[5] Al-Mashari, M., Zairi, M., \& Ginn, D. (2005). Key enablers for the effective implementation of qfd: A critical analysis. Industrial Management \& Data Systems, 105(9), 1245-1260. doi:10.1108/02635570510633284

[6] Camarillo, A., Rios, J., \& Althoff, K. D. (2018). Knowledge-based multi-agent system for manufacturing problem solving process in production plants. Journal of Manufacturing Systems, 47, 115-127. doi:10.1016/j.jmsy.2018.04.002

[7] Gangidi, P. (2019). A systematic approach to root cause analysis using 3 x 5 why's technique. International Journal of Lean Six Sigma, 10(1), 295-310. doi:10.1108/ijlss-10-2017-0114

[8] Realyvasquez-Vargas, A., Arredondo-Soto, K. C., Garcia-Alcaraz, J. L., \& Macias, E. J. (2020). Improving a manufacturing process using the $8 \mathrm{ds}$ method. A case study in a manufacturing company. Applied Sciences-Basel, 10(7). doi:10.3390/app10072433

[9] Alsyouf, I., Al-Aomar, R., Al-Hamed, H., \& Qiu, X. J. (2011). A framework for assessing the cost effectiveness of lean tools. European Journal of Industrial Engineering, 5(2), 170-197.

[10] Matsuo, M., \& Nakahara, J. (2013). The effects of the pdca cycle and ojt on workplace learning. International Journal of Human Resource Management, 24(1), 195-207. doi:10.1080/09585192.2012.674961

[11] Nascimento, D. L. D., Quelhas, O. L. G., Caiado, R. G. G., Tortorella, G. L., Garza-Reyes, J. A., \& Rocha-Lona, L. (2019). A lean six sigma framework for continuous and incremental improvement in the oil and gas sector. International Journal of Lean Six Sigma, 11(3), 577-595. doi:10.1108/ijlss-022019-0011

[12] Nedra, A., Nejib, S., Yassine, C., \& Morched, C. (2019). A new lean six sigma hybrid method based on the combination of pdca and the dmaic to improve process performance: Application to clothing sme. Industria Textila, 70(5), 447-456. doi:10.35530/it.070.05.1595

[13] Pinto, M. J. A., \& Mendes, J. V. (2017). Operational practices of lean manufacturing: Potentiating environmental improvements. Journal of Industrial Engineering and Management, 10(4 Special Issue), 550-580. doi:10.3926/jiem.2268

[14] Rafferty, B. (2009). Understanding a3 thinking: A critical component of toyota's pdca management system. Journal of Product Innovation Management, 26(2), 243-244. doi:10.1111/j.15405885.2009.00348_1.X

[15] Song, M. H., \& Fischer, M. (2020). Daily plan-do-check-act (pdca) cycles with level of development (lod) 400 objects for foremen. Advanced Engineering Informatics, 44, 12. doi:10.1016/j.aei.2020.101091

[16] Wei, W. J., Wang, S. C., Wang, H. L., \& Quan, H. J. (2020). The application of 6s and pdca management strategies in the nursing of covid-19 patients. Critical Care, 24(1), 4. doi:10.1186/s13054-020- 03124-w

[17] Anderson-Cook, C. M., Patterson, A., \& Hoerl, R. (2005). A structured problem-solving course for graduate students: Exposing students to six sigma as part of their university training. Quality and Reliability Engineering International, 21(3), 249-256. doi:10.1002/qre.666

[18] de Mast, J., \& Lokkerbol, J. (2012). An analysis of the six sigma dmaic method from the perspective of problem solving. International Journal of Production Economics, 139(2), 604-614. doi:10.1016/j.ijpe.2012.05.035 
[19] Easton, G. S., \& Rosenzweig, E. D. (2012). The role of experience in six sigma project success: An empirical analysis of improvement projects. Journal of Operations Management, 30(7-8), 481- 493. doi:10.1016/j.jom.2012.08.002

[20] Garza-Reyes, J. A. (2015). Green lean and the need for six sigma. International Journal of Lean Six Sigma, 6(3), 226-248. doi:10.1108/ijlss-04-2014-0010

[21] Guo, W., Jiang, P. Y., Xu, L., \& Peng, G. Z. (2019). Integration of value stream mapping with dmaic for concurrent lean-kaizen: A case study on an air-conditioner assembly line. Advances in Mechanical Engineering, 11(2), 17. doi:10.1177/1687814019827115

[22] Marques, P. A. D., \& Matthe, R. (2017). Six sigma dmaic project to improve the performance of an aluminum die casting operation in portugal. International Journal of Quality \& Reliability Management, 34(2), 307-330. doi:10.1108/ijqrm-05-2015-0086

[23] Delavari, S., Forghani, M., \& Mollahoseini, A. (2009). Operational Kaizen in a manufacturing company.

[24] Singh, H., Gupta, N.K. (2010) Kaizen Improvement in a Process Organization. Lambert Academic Publishing.

[25] Rahmanian, F., \& Rahmatinejad, Z. (2014). Impact of Kaizen implementation on performance of manufacturing companies' staff. European Online Journal of Natural and Social Sciences, 2(3s), 1094-1103.

[26] Abdulmouti, H. Benefits of Kaizen to business excellence: evidence from a case study (2018) Indus. Eng. Manage., 7 (2). https://proxy.univh2c.ma:2094/10.4172/2169-0316.1000251

[27] Kalva R. S., Kumar, A. P., \& Srinivasu, V. (2018). Continuous Improvement through Kaizen in a Manufacturing Organisation. Patel, V. (2017). Review on Implementation of Kaizen Technique for Productivity Improvement in Manufacturing Organization (Vol. V).

[28] Rahmanian, F., \& Rahmatinejad, Z. (2014). Impact of Kaizen implementation on performance of manufacturing companies' staff. European Online Journal of Natural and Social Sciences, 2(3s), 1094-1103.

[29] Ishikawa, K. (1984) la gestion de la qualité. Outils et applications pratiques. Paris: Dunod.

[30] Ohno T (1978) Toyota production system. Diamond-Press, Tokyo

\begin{abstract}
AUTHOR
Mohammed HAMOUMI (40 years old). 2001/2005 Lille Polytechnic University Graduate Engineering School, France. 2011/2013 EHTP/ENPC MBA- School of International Management Paris. 7 years at STMicroelectronics as Quality Assurance and Customer Quality Support Manager. 3 years at LEONI Wiring Systems as Plant Quality Manager. 3 years at CIF (Plastic Industry. Leader in the manufacture of woven polypropylene (PP) bags and kraft paper bags) as Quality Director. 2 years at PSA Morocco as Quality and Engineering Director Since June 2018 Lead Auditor BUREAU VERITAS and trainer certified resolutions problems. Certified Lead Auditor IRCA ISO 9001, ISO 14001, ISO 45001, IATF 16949 V2016.
\end{abstract}

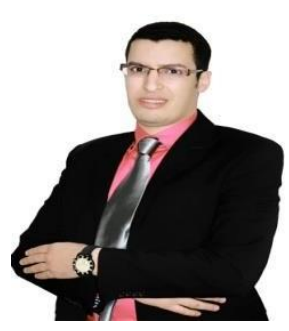

